\title{
DETECCIÓN DE PLAGAS FORESTALES EN EL BOSQUE TEMPLADO DEL NORESTE DE MÉXICO MEDIANTE IMÁGENES SATELITALES DE ALTA RESOLUCIÓN
}

Eduardo Treviño', Gerardo Cuellar ${ }^{2}$, Oscar Aguirre $^{3}$ y Javier Jiménez ${ }^{4}$

\section{RESUMEN}

La incidencia y dispersión de plagas forestales en los bosques templados es favorecida por fenómenos naturales, como son las sequias y los incendios. El desequilibrio causado por estos fenómenos produce las condiciones necesarias para el ataque de insectos. Los patrones de distribución de las plagas tienen una naturaleza espacial y hacen necesaria su cartografia y monitoreo para tomar las medidas necesarias para su control. El uso de la percepción remota hace posible evaluar los cambios cuantitativos y cualitativos de la vegetación.

El objetivo de este trabajo fue detectar y cuantificar las áreas afectadas por descortezadores y otras plagas forestales en masas arboladas de la Sierra Madre Oriental del noreste de México, utilizando el procesamiento digital de imágenes y validando los resultados con información levantada en campo.

Se realizó un vuelo en helicóptero para localizar de manera visual los focos de infección de las plagas, los sitios detectados fueron utilizados como referencia para el procesamiento de interpretación de las imágenes de satélite. La información se apoyo en la contenida en las cartas de vegetación producidas por el inventario forestal. Se preparó mapas para la planeación de las visitas en campo, las cuales fueron realizadas a las áreas forestales infectadas detectadas. Durante la visita de campo se recolectó los insectos hospedados en los árboles infectados. De la misma manera se tomó parámetros dasométricos para el posterior análisis de las comunidades vegetales. Se registró de la misma manera las coordenadas de los sitios visitados. Como resultado se obtuvo la caracterización dasométrica de las áreas infectadas y se analizó el comportamiento espacial de las plagas forestales detectadas en la Sierra Madre Oriental en el sur de Nuevo León.

Palabras clave: Plagas forestales, imágenes de alta resolución, QuickBird, México

\footnotetext{
1 Facultad de Ciencias Forestales, Universidad Autónoma de Nuevo León, México, eitrevin@fcf.uanl.mx

2 gcuellar@fcf.uanl.mx

3 oaguirre1@prodigy.net.mx

4 jijmenez20@prodigy.net.mx
} 


\section{DETECTION OF FOREST PLAGUES IN THE TEMPERATE FORESTS IN THE NORTHEAST OF MEXICO USING HIGH RESOLUTION SATELLITE IMAGES}

\section{SUMMARY}

The incidence and dispersion of forest plagues in the temperate forests are favored by natural phenomena, like droughts and fires. The imbalance caused by these phenomena produces the necessary conditions for the insects attack. The distribution patterns of the plagues have an especial nature and to take the measures for their control is necessary their cartography and monitoring. The use of the satellite remote sensing makes possible to evaluate the quantitative and qualitative changes of the vegetation.

The objective of this work was to detect and to quantify the affected areas by bark beetles and other forest plagues in forest of the Sierra Madre Oriental in the northeast of Mexico using the digital processing of satellite images, validating the results with field information.

A flight in helicopter was carried out to find the focuses of infection of the plagues; the detected places were used as a reference for the interpretation processing of the satellite images. Forest maps were prepared to planning the field work, in which infected forest areas were detected. During the field work the insects were collected from the infected trees. Tree parameters were measure for the analysis of the vegetation community. In each sampling plot the coordinates were registered. As results the tree characterization of the infected areas were obtained and the space behavior of the forest plagues was analyzed.

Key words: Forest plague, high resolution satellite images, QuickBird, Mexico 


\section{INTRODUCCIÓN}

El manejo forestal involucra mantener el bosque en condiciones apropiadas para su desarrollo óptimo, que permita cosechar bienes tangible, como madera y otros productos forestales, asi como obtener los servicios ambientales, como captura de carbono y producción de agua. Los bosques están expuestos a diversas plagas y enfermedades forestales de manera natural. En áreas subtropicales los periodos de sequía no solo incrementan el peligro de incendios forestales, sino que favorecen el ataque de insectos a los individuos debilitados por el estrés hidrico.

Los patrones de infestación de las plagas de insectos se manifiestan en las copas de los árboles al mostrar esta amarillamiento. Por lo general estas infestaciones provocan claros en el dosel del bosque.

El uso de fotografias aéreas se ha empleado en el manejo forestal en general y en la patologia forestal en particular para analizar los patrones de distribución de las comunidades vegetales y de su condición sanitaria, utilizando para ese efecto fotografías aéreas infrarrojas, con las cuales es posible determinar patrones de infestación del arbolado expresados en alternaciones en la reflectancia del follaje.

La naturaleza multiespectral de las imágenes de satélite permite de la misma manera detectar cambios en la reflexión de la cubierta vegetal a nivel comunidad, sin embargo dada la baja resolución espacial que presentaban no era posible determinar afectaciones a nivel puntual en árboles individuales.

Las infestaciones de barrenadores en los bosques mixtos pino encino del noreste de México se presentan en su etapa inicial afectando pocos individuos. Con la disponibilidad actual de imágenes de alta resolución proporcionadas por el satélite QuickBird se plantea como posible el evaluar datos individuales de las copas de los árboles

\section{OBJETIVOS}

El objetivo de este trabajo fue detectar y cuantificar las áreas afectadas por descortezadores y otras plagas forestales en masas arboladas de la Sierra Madre Oriental del noreste de México, utilizando el procesamiento digital de imágenes y validando los resultados con información levantada en campo.

\section{ANTECEDENTES GENERALES}

La patologia forestal implica de manera directa el ser observada, desde una perspectiva de paisaje, a causa de que los organismos patógenos que afectan al arbolado se propagan de acuerdo a patrones espaciales heterogéneos de flujo y aislamiento (Holdenrieder et al., 2004).

La infestación de algunas plagas forestales se manifiesta con la afectación del follaje que en una primera etapa no es detectable a simple vista, cuando se presenta el amarillamiento 
del mismo la muerte del árbol ha sucedido o es inminente.

En el caso de los insectos barrenadores de la corteza, los eventos de sequia extrema o el estrés causado por incendios forestales son las causas que provocan la infestación, hecho que ha sido analizado en Estados Unidos (Gibson, 2004, Breshears et al. 2005), aunque las causas que propician la dispersión de la plaga dentro del bosque tienden a diferir de las que la provocan, en la mayoria de los casos es atribuible a la dirección y fuerza de los vientos.

Con disponibilidad a partir de 1998 de imágenes con resolución de $1 \mathrm{~m}$ se ha posibilitado la diferenciación de clases de edades dentro del bosque (Franklin et al., 2001) y la separación de especies (Masato, 2004).

\section{MATERIAL Y MÉTODO}

Nuevo León, situado en el noreste de México, cuenta con una superficie que corresponde al $3.3 \%$ del pais. Un $18.5 \%$ tiene vocación forestal maderable de la cual la mitad se concentra en los mezquitales y la mitad corresponde a bosques templados. De esta área solo el $6 \%$ se encuentra sujeto a actividades forestales comerciales. La distribución de los bosques en un àrea subtropical como Nuevo León obedece en general a una distribución altitudinal, en general los bosques son mixtos de pino-encino, en diferentes proporciones de mezcla y las masas puras de coniferas se restringen a pequeñas superficies, que si son comparadas con los bosques de esta región son de baja productividad, lo cual obedece en general a cuestiones climáticas y a fuertes disturbio, como son la ganaderia extensiva y los incendios recurrentes. El estrés de los bosques causado por las sequias y los incendios recurrentes provocan el que ejemplares se vean afectados por plagas forestales.

El estado de Nuevo León esta situado en el noreste de la República Mexicana, entre los paralelos $27^{\circ} 48^{\prime}$ y $23^{\circ} 09^{\prime}$ de Latitud Norte y los meridianos $98^{\circ} 26^{\circ}$ y $101^{\circ} 13^{\prime}$ de Longitud Oeste . (SEP, 1997). La mayor parte del estado se encuentra dentro de los climas considerados secos y semisecos, la región es considerada con temperaturas promedio altas, oscilación mensual y diaria muy extremas y en invierno la región es influenciada por masas de aire polar continental que provocan descensos de temperatura abruptos acompañados por niebla, nublados fuertes y lluvia ligera. La lluvia se presenta en los meses de septiembre y octubre (verano), el porcentaje de lluvia invernal es reducido.

Para localizar de manera visual los focos de infección de las plagas se realizó un vuelo en helicóptero, los sitios detectados fueron utilizados como referencia para el procesamiento de interpretación de las imágenes de satélite. Se contó con un juego de imágenes de satélite SPOT del año 2004 para toda la región del estado. Se seleccionó un área piloto en la cual fue tomada una imagen QuickBird, en septiembre de 2005.

La información se apoyo en la contenida en las cartas de vegetación producidas por el inventario forestal. Se preparó mapas para la planeación de las visitas en campo a las ảreas forestales infectadas detectadas. Durante la visita de campo. se evaluó sitos circulares tomando como centro el árbol infestado en donde se registró diámetro, altura total del árbol, altura del 
fuste limpio y dos diámetros de copa. Se tomó nota de las coordenadas de los sitios visitados, asi como de otras generalidades del cada uno de los sitos, como pendiente, pedregosidad, exposición, altitud y alteraciones del medio ambiente como incendios o la presencia de ganado. etc.

La condición sanitaria de los árboles afectados fue detectada con la presencia de grumos en el fuste los cuales son indicadores de infestación, la fase de infestación se determinó considerando la coloración del grumo, se recolectó los insectos hospedados en los árboles infectados para lo cual se removió parte de la corteza y se colectó de 10 a 15 ejemplares de larvas y adultos ( 20 a 30 en total). Se calculó también el porcentaje de follaje de la copa afectado para cada ejemplar.

Se desplegó los sitios visitados en campo sobre las imágenes de satélite con la finalidad de tratar de determinar la variabilidad espectral de los árboles infestados con respecto a su entorno. Toda la información fue almacenada en una base de datos georeferenciada y se analizó la información para determinar las prioridades de manejo de la plaga en las áreas afectadas.

\section{RESULTADOS Y DISCUSIÓN}

En total fueron visitados 220 sitios; 162 de bosques templados y 58 de mezquitales. Las especies arboréas dominantes en los bosques fueron en su mayoria pertenecientes al genero Pinus, encontrándose infestaciones en 75 sitios de $P$. pseudostrobus, en 54 de $P$. cembroides, y en 29 de $P$. teocote, de igual forma se encontró dos sitios en donde la especie hospedera era Abies religiosa y dos en que lo era Carya mexicana. 


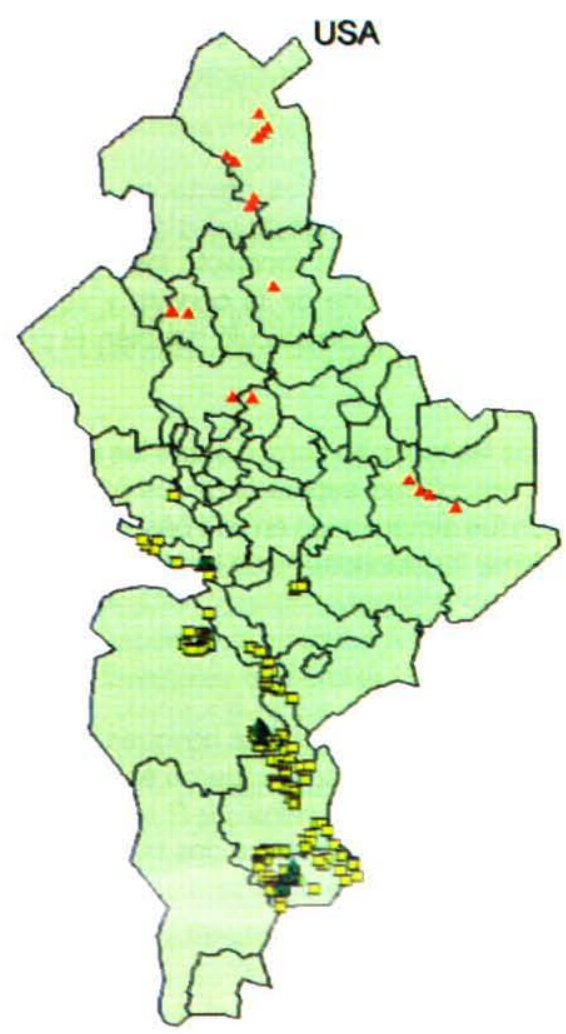

Figura $\mathrm{N}^{\circ} 1$

\section{UBICACIÓN DE LOS SITIOS DE COLECTA \\ LOS PUNTOS ROJOS INDICAN AREAS DE MEZQUITALES \\ LOS PUNTOS AMARILLOS Y VERDES ÁREAS DE BOSQUE TEMPLADO}

La densidad del arbolado se encontró en un rango entre 70 y 600 árboles por hectárea, encontrándose en promedio entre 5 y 7 árboles infestados por sitio. El diámetro promedio de los árboles en donde se presentó la infestación varió de 25,3 en los bosques de $P$. cembroides a 32,5 en los de Abies religiosa, considerando un promedio de $30 \mathrm{~cm}$. La altura promedio del arbolado fue de $15 \mathrm{~m}$.

La ubicación de los sitos fue empleada para hacer el análisis de las firmas espectrales en la imagen SPOT y QuickBird. En ambas existieron dificultades para determinar de manera exacta la respuesta de los árboles al estrés. En cuanto a la naturaleza con la que se presentan las infestaciones afectando pocos árboles en las imágenes SPOT, la resolución de $10 \mathrm{~m}$ impidió discriminar de manera exacta los árboles afectados. Con las imágenes QB la mejor resolución espectral permite discriminar árboles individuales, con lo que fue posible separar los árboles infestados. 
La base de datos georeferenciada permitió manejar la información para realizar el análisis considerando variables topográficas, además de las levantadas en el trabajo de campo, la Figura $\mathrm{N}^{\circ} 3$ muestra una consulta de la información de un sitio.

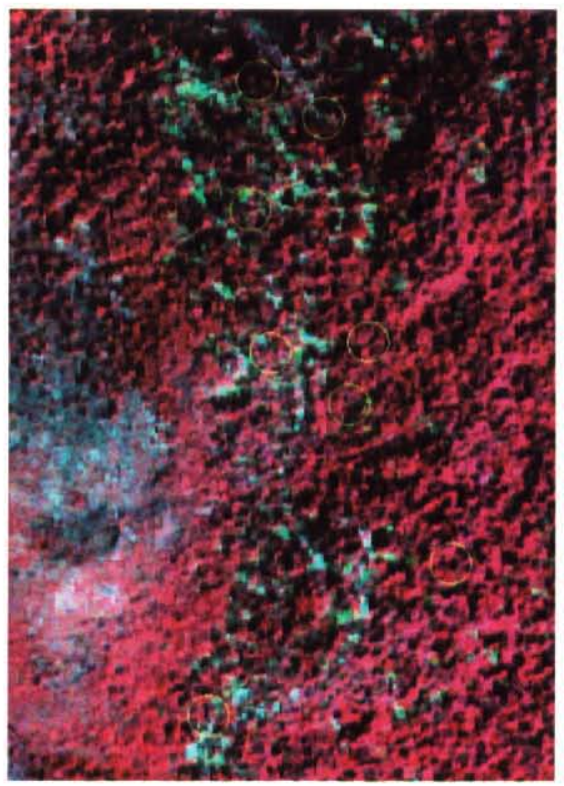

Figura $\mathrm{N}^{\circ} 2$

IMAGEN QUICKBIRD MOSTRANDO EN LOS CIRCULOS AMARILLOS LOS SITIOS MUESTREADOS.

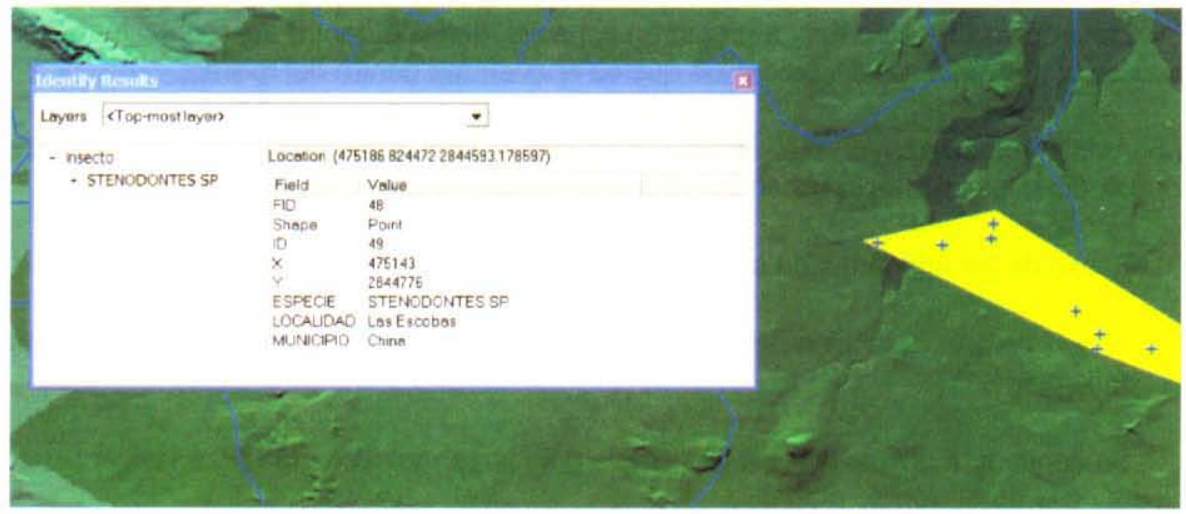

Figura $\mathrm{N}^{\circ} 3$

CONSULTA DE LA INFORMACIÓN DE UN SITIO DE MUESTREO, LAS PUNTOS EN FORMA DE CRUZ REPRESENTAN LOS SITIOS 
El análisis espacial de las caracteristicas de las infestaciones permitió priorizar las acciones a realizar para el saneamiento de las áreas afectadas, se unió los puntos con afinidades espaciales y caracteristicas biológicas similares, para formar poligonos, los cuales se presentan en la Figura $\mathrm{N}^{\circ} 4$, en color rojo las zonas con mayor prioridad y en amarillo y verde las de mediana y baja prioridad, respectivamente.

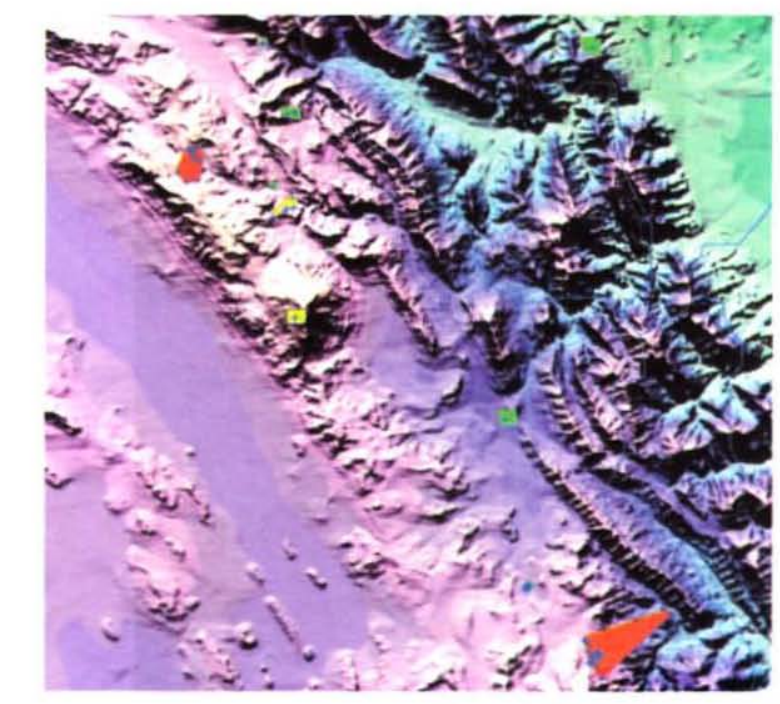

Figura $\mathrm{N}^{\circ} 3$

PRIORIDADES DE SANEAMIENTO PARA ÁREAS AFECTADAS

\section{CONCLUSIONES}

Las infestaciones no tienen un patrón espacial definido dentro del rodal, afecta tanto a árboles en el límite del rodal, como a los que se encuentran dentro del mismo.

Afecta en su mayoria a árboles maduros y con diámetros superiores a $30 \mathrm{~cm}$, restringiéndose las infestaciones en un $15 \%$ a dimensiones menores.

El uso de las imágenes de satélite permitió optimizar las actividades en campo.

El uso para la detección directa de las infestaciones se vio limitado por la naturaleza propia de la plaga.

Se continuará aplicando esta tecnología bajo otras metodologias para validar el uso de la misma en la detección de plagas. 


\section{REFERENCIAS}

Holdenrieder,Tomar; Pautaos, Marco; Weisberg, Peter J. and David Lonsdale, 2004. Tree diseases and landscape processes: the challenge of landscapepathology. Trends in Ecology and Evolution Vol.19 No.8 August 2004, p 446-452.

Mc Dougall, K. L.; Hobbs, R. J. and G. E. St J. Hardy., 2005. Distribution of understorey species in forest affected by Phytophthora cinnamomi in south-western Western Australia, Australian Journal of Botany 53(8) 813-819

Worrall, James J., D. Lee Thomas and Thomas, C. Harrington, 2004. Forest dynamics and agents that initiate and expand canopy gaps in Picea-Abies forests of Crawford Notch, New Hampshire, USA Journal of Ecology. Volume 93, P 178 -

Gibson, Ken, 2004. Bark Beetle Conditions Northern Region. En linea Agosto 2006: http://www.fs.fed.us/ r1-r4/spf/fhp/publications/byregion/bbcond04.pdf

Sturdevant, Nancy and Sandra, Kegley, 2006. Mapping Mountain Pine Beetle and White Pine Blister Rust in White Bark Pine on the Helena National Forest. Numbered Report 06-05 USDA Forest Service, Forest Health Protection. En linea agosto 2006:

http://www.fs.fed.us/r1-r4/spf/fhp/publications/bystate/R1Pub06-05_Mapping_MPB_WPBrust_WBP.pdf

Franklin, S. E.; Wulder, M. A. y G. R. Gerylo, 2001. Texture Analysis of IKONOS Panchro Matic Data for Dowglas-fir forest age class separability in British Columbia, International journal of remote sensing Vol. 22 num.13/pp 2627-2632.

Masato, Katoh, 2004. Classifying tree species in a northern mixed forest using high-resolution IKONOS data Journal of Forest Research Volume 9, number 1, pp 7-14 Publisher: Springer-Verlag.

SEP, 1997. Secretaria de Educación Pública Nuevo León, Monografia estatal, México, D. F. 220 p. 